\title{
Economic Consequences of Non-Communicable Diseases at Household Level: A Case Study Among Adults of Some Households in Bangladesh
}

\author{
Bhuyan Keshab Chandra \\ Department of Statistics, Jahangirnagar University, Dhaka, Bangladesh \\ Email address: \\ kcbhuyan2002@yahoo.com
}

\section{To cite this article:}

Bhuyan Keshab Chandra. Economic Consequences of Non-Communicable Diseases at Household Level: A Case Study Among Adults of Some Households in Bangladesh. American Journal of Data Mining and Knowledge Discovery. Vol. 4, No. 2, 2019, pp. 63-69.

doi: 10.11648/j.ajdmkd.20190402.12

Received: October 23, 2019; Accepted: November 13, 2019; Published: November 19, 2019

\begin{abstract}
The objective of the present study was to investigate the economic consequences of non-communicable diseases of adults at household level. According to the objective of the study the analysis was done using data collected from 808 adults of Bangladesh who were investigated by some doctors and nurses from and nearby their working places. Among these adults 49.6 percent were suffering from at least one of the non-communicable diseases. The most common non-communicable disease was diabetes. The percentage of exclusive diabetic patients among NCDs affected adults was 55.9 followed by diabetic-cum-heart (14.0\%) and diabetic- cum- kidney (9.5\%) patients. The percentage of admitted NCDs patients in hospital was 71.1 and they were treated for, on an average, 4.72 days incurring an opportunity loss of 37.75 working hours. The economic loss per month for treatment was Tk.3030.21. This economic loss was 4.04 percent of the monthly family income. The economic loss and the opportunity loss due to hospital admission was the economic burden to the individual household.
\end{abstract}

Keywords: Obesity, Non-communicable Diseases, Economic Loss, Opportunity Loss, Economic Burden

\section{Introduction}

Non-communicable diseases are chronic diseases which last, in many cases, for long time. Sometimes the incidence of death occurs rapidly, like the death due to stroke and heart attack. There are four main types of NCDs and these are (i) cardiovascular diseases, (ii) cancer, (iii) chronic respiratory diseases, and (iv) diabetes. The key diseases of NCDs are cancer, cardiovascular diseases, chronic kidney diseases [CKD]. But CKD is a contributing factor to the incidence and outcomes of at least three of the diseases targeted by WHO [1]. These three are diabetes, hypertension, and cardiovascular diseases.

In a separate study, it was noted that most of the Bangladeshi urban adults were suffering from diabetes $(36.3 \%)$ [2]. Very few $(3.1 \%)$ were suffering from heart disease and from hypertension $(0.6 \%)$. The prevalence of diabetes in adults (20-79 years of ages) was 7.4 per cent in Bangladesh [3-4]. According to International Diabetes Federation the prevalence of diabetes will be 13 per cent by
2030 [5-6]. It indicates that there will be rapidly growing burden of NCDs in developing countries. The problem is accelerated by population ageing, negative effects of globalization (unfair trade and irresponsible marketing), rapid and unplanned urbanization, increased sedentary lives, change of food habit preferring higher levels of total energy and preferring foods high in salt, fat and sugar and physical inactivity. Thus NCDs are considered as the diseases of rich. But NCDs are now leading cause of death in low - and middle-income countries. The disease kills 41 million people annually and this amount is equivalent to 71 per cent of all deaths in a year [2]. Each year 15 million die from NCDs between the ages of 30 to 69 years which affects the labor supply. Over 85 per cent of this premature deaths occur in low- and middle-income countries [2]. In the next decade, the death will be increased up to 24 percent and it will affect severely in the developing countries [7]. Thus economists are increasingly expressing concern that NCDs will result in long term macroeconomic impacts on labor supply, capital accumulation and GDP worldwide with the consequences 
most severe in developing countries [8 - 12]. Globally, the labor units lost owing to NCDs deaths and the direct medical cost of treating NCDs have reduced the quality and quantity of labor force and human capital [10].

At the household level, unhealthy behaviors, poor physical status, and the high cost of NCDs related health care, lead to loss of household income [13-14]. Thus, NCDs have a major public health concern in many low-and- middle-income countries. Out-of pocket expenditure associated with the acute long term effects of NCDs is high, resulting in catastrophic health expenditure for the households [13 -15]. In India the income loss due to hypertension is the highest, followed by diabetes and cardiovascular diseases (CVD). The macroeconomic impact of NCDs is profound as they are the cause of loss of productivity and decreasing gross domestic product (GDP)and hence the attempts of developing nation to eradicate poverty are hindered due to significant loss of productivity caused by NCDs related premature deaths and treatments $[13,16]$. The economic burden on households of NCDs including diabetes and CVD poses major challenges in alleviating poverty.

There are some studies on the economic burden of NCDs at macroeconomic level including financial and working hour loss [8-18]. Most of the studies were done at national level. No similar study was noted from small scale sample survey which could reflect the family loss in terms of money and opportunity loss from loss of labor hours. The present analysis was an attempt to guess some socioeconomic aspects of prevalence of NCDs so that economic loss and opportunity loss due to loss of labor hours could be guessed for those families from which some adults were admitted in the hospital. The per capita cost of treatment could reflect the per capita family economic loss.

\section{Methodology}

The analytical results presented in the paper was based on data collected from 808 adults of Bangladesh who were investigated by some doctors and nurses from their working places according to their convenience. The data were collected during academic session 2016-2017 when the investigators were continuing their academic carrier as M.P.H. students. The investigators were instructed to collect information from the persons of ages 18 years and above. The data were recorded through a pre-designed and pretested printed questionnaire. The collected information from all the investigated adults were related to different socioeconomic variables including monthly family income and yearly family expenditure on treatment of noncommunicable diseases. The data on hospital admission of investigating units for treatment of any of the NCDs were also recorded. Some of the variables were qualitative in nature. But for analytical purpose all the variables were noted in nominal scores.

In some studies, both in home and abroad, it was noted that NCDs were associated with body mass index (BMI) [5, 19, 21-23]. The body mass index was measured by weight in $\mathrm{kg} /$ height in $(\mathrm{m})^{2}[2,20]$. The adults were classified as underweight $[\mathrm{BMI}<20]$, normal weight $[\mathrm{BMI}=20-<25]$, overweight $[\mathrm{BMI}=25-<30]$ and obese [BMI $>30]$ [2]. The association of level of obesity with different types of NCDs was investigated by Chi-square test. The association of NCDs with some of the socioeconomic variables was also investigated by the same test, where significant association was decided when $\mathrm{p}$ - value of a Chi-square test statistic $\leq$ 0.05 . The average family income, average cost of treatment per family and average loss of working hours by the investigating units due to hospital admission were calculated to guess the financial and opportunity loss.

\section{Results}

From the analysis, it was noted that 49.6 percent adults were suffering from at least one of the non-communicable diseases. Among this group 55.9 percent were suffering exclusively from diabetes, 8.5 percent had heart problem, 14.4 percent were suffering from diabetes and heart problem, 12.2 percent had the problems of diabetes, hypertension, heart and other NCDs, and 9.5 percent were suffering from diabetes and kidney diseases. Among the investigated adults 69.7 percent were males and 25.9 percent of them were diabetic. Another 12.3 percent of them were suffering from diabetes, heart and kidney diseases at the same time. The corresponding percentages among females were less except the female patients of diabetes and kidney. However, there was no significant differences in the prevalenoe of different types of NCDs among males and females $\left[\chi^{2}=10.835\right.$, pvalue $=0.055]$. The risk ratio $[R . R=0.87]$ indicated that male and female adults had almost similar risk of prevalence of NCDs.

Among the investigated adults 50.4 percent were free of any of the NCDs and there was no question of treatment or admission into hospital for treatment. This was noted from Table 1. However, 64.7 percent of the adults were never admitted to the hospital. It indicated that 28.9 percent NCDs affected adults were never admitted to the hospital. The admitted patients, on an average, were 4.72 days in the hospital (standard deviation of stay in hospital was 4.35 days) and they lost, on an average, 37.76 labor hours throughout the year due to the suffering from NCDs. The 95 percent confidence interval of stay in hospital was [-3.82, 13.25] days. The loss of labor hours was approximately weekly labor hours at national level [39 hours per week] [24]. There was significant association between duration of stay in hospital and prevalence of NCDs [ $\chi^{2}=503.283$, pvalue $=0.000]$. 
Table 1. Distribution of adults according to duration of stay in hospitals, type of diseases, expenditure for the treatment of the diseases and family income.

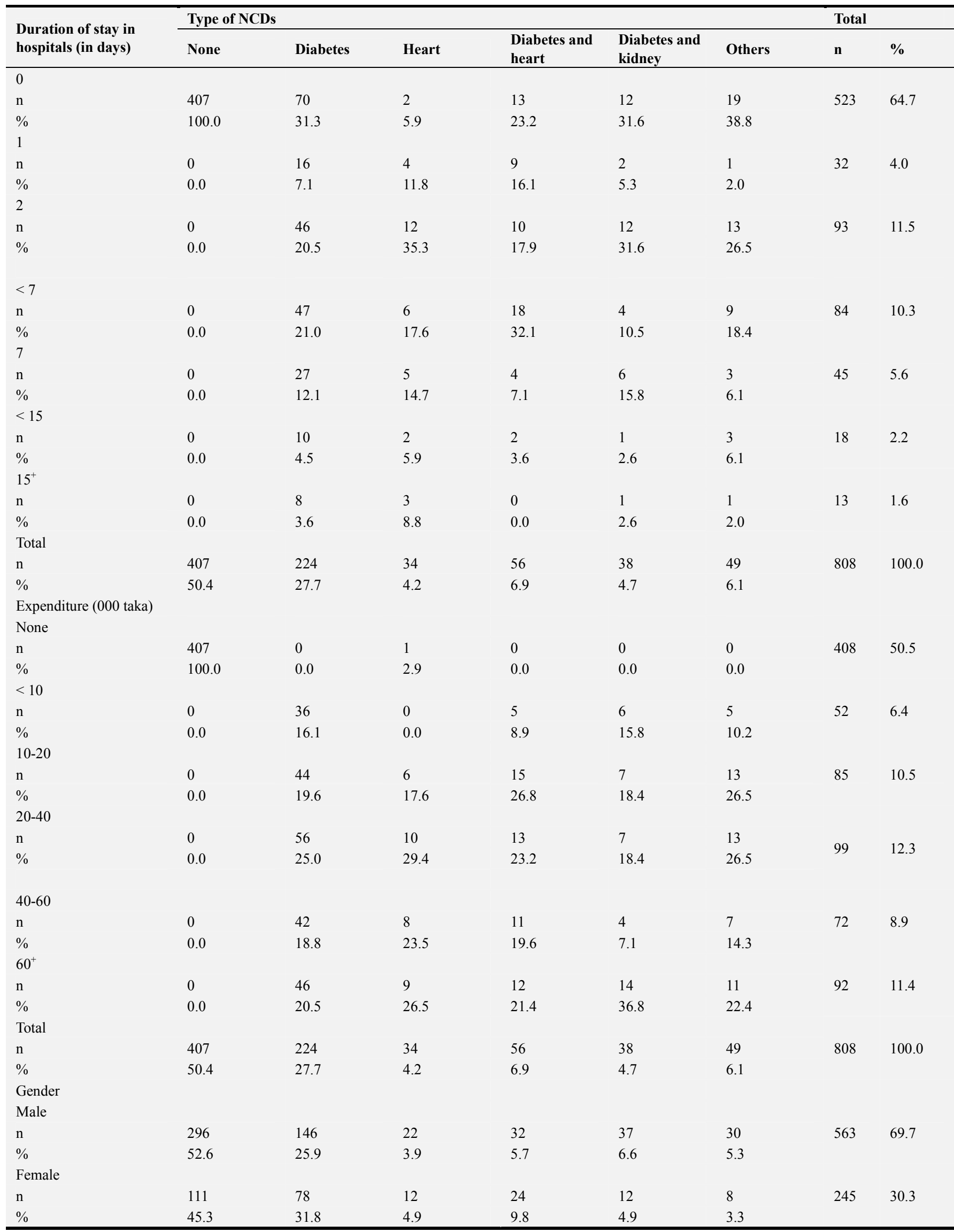


Table 1. Continued.

\begin{tabular}{|c|c|c|c|c|c|c|c|c|}
\hline \multicolumn{9}{|c|}{ Family income } \\
\hline$<30$ & & & & & & & & \\
\hline $\mathrm{n}$ & 96 & 36 & 7 & 9 & 4 & 7 & 159 & 19.7 \\
\hline$\%$ & 60.4 & 22.6 & 4.4 & 5.7 & 2.5 & 4.4 & & \\
\hline \multicolumn{9}{|l|}{$30-60$} \\
\hline $\mathrm{n}$ & 55 & 33 & 9 & 8 & 6 & 5 & 116 & 14.4 \\
\hline$\%$ & 47.4 & 28.4 & 7.8 & 6.9 & 5.2 & 4.3 & & \\
\hline \multicolumn{9}{|l|}{$60-90$} \\
\hline$\%$ & 37.1 & 33.9 & 11.3 & 3.2 & 8.1 & 6.5 & & \\
\hline \multicolumn{9}{|l|}{$90^{+}$} \\
\hline $\mathrm{n}$ & 233 & 134 & 11 & 37 & 23 & 33 & 471 & 58.3 \\
\hline$\%$ & 49.5 & 28.5 & 2.3 & 7.9 & 4.9 & 7 & & \\
\hline \multicolumn{9}{|l|}{ Total } \\
\hline $\mathrm{n}$ & 407 & 224 & 34 & 56 & 38 & 49 & 808 & 100 \\
\hline$\%$ & 50.4 & 27.7 & 4.2 & 6.9 & 4.7 & 6.1 & & \\
\hline
\end{tabular}

The diabetic patients, on an average, were 4.97 days in the hospitals [ $\sigma=4.50$ days]. The averages of duration of stay in the hospitals by the patients of heart, diabetes-cum-heart, diabetescum-kidney, and other diseases were, respectively, 5.34 ( $\sigma=$ 5.50), $3.56(\sigma=2.54), 4.46(\sigma=4.09)$ and $5.67(\sigma=2.66)$. It was observed that those who were suffering from multiple diseases, they were staying in the hospital for more duration.

Among the investigated adults 64.7 percent [Table 2] adults were never admitted in the hospital but 50.5 percent had no medical expenditure. This implied that, though some NCDs affected adults were not admitted in the hospital, still they had expenditure for treatment. A major (12.3\%) group of patients spent around 20-40 thousand taka per year. The average medical expenditure per NCDs affected adult was $36,326.50$ taka per year or 3030.21 taka per month ( $\sigma=$ $22,990.89$ taka / year). This amount was the economic burden in the families, where these families had income, on an average, 72,000.00 taka/month ( $\sigma=47,339.20$ taka/month). Around four (4.04\%) percent of the family income was lost for the treatment of NCDs. This was the medical cash expenditure for the patient, but there was hidden loss of money due to the loss of labor hour. This loss of labor hour was the opportunity loss to the family and it was another economic burden on the family.

Table 2. Distribution of adults according to some social characters and duration of stay in hospitals.

\begin{tabular}{|c|c|c|c|c|c|c|c|c|}
\hline \multirow{2}{*}{ Socioeconomic character } & \multicolumn{8}{|c|}{ Duration of stay in hospital (in days) } \\
\hline & None & 1 & 2 & $<7$ & 7 & $7-15$ & $15^{+}$ & Total \\
\hline \multicolumn{9}{|l|}{ Gender } \\
\hline \multicolumn{9}{|l|}{ Male } \\
\hline $\mathrm{n}$ & 380 & 18 & 55 & 60 & 29 & 10 & 11 & 563 \\
\hline$\%$ & 67.5 & 3.2 & 9.8 & 10.7 & 5.2 & 1.8 & 2.0 & 69.7 \\
\hline \multicolumn{9}{|l|}{ Female } \\
\hline $\mathrm{n}$ & 143 & 14 & 38 & 24 & 16 & 8 & 2 & 245 \\
\hline$\%$ & 58.4 & 5.7 & 15.5 & 9.8 & 6.5 & 3.3 & 0.8 & 30.3 \\
\hline \multicolumn{9}{|l|}{ Age (in years) } \\
\hline \multicolumn{9}{|l|}{$<20$} \\
\hline $\mathrm{n}$ & 23 & 1 & 6 & 1 & 3 & 2 & 0 & 36 \\
\hline$\%$ & 63.9 & 2.8 & 16.7 & 2.8 & 8.3 & 5.6 & 0.0 & 4.5 \\
\hline \multicolumn{9}{|l|}{$20-30$} \\
\hline $\mathrm{n}$ & 244 & 6 & 15 & 31 & 13 & 2 & 1 & 312 \\
\hline$\%$ & 78.2 & 1.9 & 4.8 & 9.9 & 4.2 & 0.6 & 0.3 & 38.6 \\
\hline \multicolumn{9}{|l|}{$30-40$} \\
\hline $\mathrm{n}$ & 51 & 3 & 8 & 2 & 2 & 0 & 0 & 66 \\
\hline$\%$ & 77.3 & 4.5 & 12.1 & 3.0 & 3.0 & 0.0 & 0.0 & 8.2 \\
\hline \multicolumn{9}{|l|}{$40-50$} \\
\hline $\mathrm{n}$ & 90 & 8 & 22 & 7 & 7 & 1 & 3 & 138 \\
\hline$\%$ & 65.2 & 5.8 & 15.9 & 5.1 & 5.1 & 0.7 & 2.2 & 17.1 \\
\hline \multicolumn{9}{|l|}{$50^{+}$} \\
\hline $\mathrm{n}$ & 115 & 14 & 42 & 43 & 20 & 13 & 9 & 256 \\
\hline$\%$ & 44.9 & 5.5 & 16.4 & 16.8 & 7.8 & 5.1 & 3.5 & 31.7 \\
\hline \multicolumn{9}{|l|}{ Level of obesity } \\
\hline \multicolumn{9}{|l|}{ Underweight } \\
\hline $\mathrm{n}$ & 88 & 2 & 6 & 5 & 4 & 0 & 2 & 107 \\
\hline$\%$ & 82.2 & 1.9 & 5.6 & 5.7 & 3.7 & 0.0 & 1.9 & 13.2 \\
\hline \multicolumn{9}{|l|}{ Normal } \\
\hline $\mathrm{n}$ & 268 & 19 & 49 & 34 & 19 & 11 & 5 & 405 \\
\hline$\%$ & 66.2 & 4.7 & 12.1 & 8.4 & 4.7 & 2.7 & 1.2 & 50.1 \\
\hline Overweight & & & & & & & & \\
\hline
\end{tabular}


Table 2. Continued.

\begin{tabular}{|c|c|c|c|c|c|c|c|c|}
\hline \multirow{2}{*}{ Socioeconomic character } & \multicolumn{8}{|c|}{ Duration of stay in hospital (in days) } \\
\hline & None & 1 & 2 & $<7$ & 7 & $7-15$ & $15^{+}$ & Total \\
\hline $\mathrm{n}$ & 147 & 10 & 34 & 40 & 19 & 6 & 5 & 261 \\
\hline$\%$ & 56.3 & 3.8 & 13.0 & 15.3 & 7.3 & 2.3 & 1.9 & 32.3 \\
\hline \multicolumn{9}{|l|}{ Obese } \\
\hline $\mathrm{n}$ & 20 & 1 & 4 & 5 & 3 & 1 & 1 & 35 \\
\hline$\%$ & 57.1 & 2.9 & 11.4 & 14.3 & 8.6 & 2.9 & 2.9 & 4.4 \\
\hline \multicolumn{9}{|l|}{ Used to take can food } \\
\hline \multicolumn{9}{|l|}{ Yes } \\
\hline $\mathrm{n}$ & 352 & 15 & 69 & 44 & 21 & 12 & 9 & 522 \\
\hline$\%$ & 67.3 & 46.9 & 74.2 & 52.4 & 46.7 & 66.7 & 69.2 & 64.6 \\
\hline \multicolumn{9}{|l|}{ No } \\
\hline $\mathrm{n}$ & 171 & 17 & 24 & 40 & 24 & 6 & 4 & 286 \\
\hline$\%$ & 32.7 & 53.1 & 25.8 & 47.6 & 53.3 & 33.3 & 30.8 & 35.4 \\
\hline \multicolumn{9}{|l|}{ Used to take restaurant food } \\
\hline \multicolumn{9}{|l|}{ Yes } \\
\hline $\mathrm{n}$ & 325 & 12 & 62 & 39 & 20 & 11 & 6 & 475 \\
\hline$\%$ & 62.1 & 37.5 & 66.7 & 46.4 & 44.4 & 61.1 & 46.2 & 58.8 \\
\hline \multicolumn{9}{|l|}{ No } \\
\hline $\mathrm{n}$ & 198 & 20 & 31 & 45 & 25 & 7 & 7 & 333 \\
\hline$\%$ & 39.9 & 62.5 & 33.3 & 53.6 & 54.6 & 38.9 & 53.8 & 41.2 \\
\hline \multicolumn{9}{|l|}{ Total } \\
\hline $\mathrm{n}$ & 523 & 32 & 93 & 84 & 45 & 18 & 13 & 808 \\
\hline$\%$ & 64.7 & 4.0 & 11.5 & 10.4 & 5.6 & 2.2 & 1.6 & 100.0 \\
\hline
\end{tabular}

The averages of expenditure for patients of diabetes, heart, diabetes-cum-heart, diabetes-cum-kidney and patients of other diseases were, respectively, 35,000.00 ( $\sigma=22873.88)$, $34848.48(\sigma=32274.51), 21142.86(\sigma=36952.40)$, $39421.05(\sigma=26936.70)$ and $28142.86(\sigma=31082.84)$ taka per year. It was noted that the maximum expenditure was incurred to the patients of diabetes-cum- kidney. It was noted that 11.4 percent adults spent minimum Tk. 60,000.00. In this group 50 percent were exclusively diabetic patients. It was already mentioned that the patients of NCDs were admitted, on an average, for 4.72 days [Table 2].

The average stay of male patients was 4.98 days and this average for female patients was 4.25 days. The mail patients were staying more times in the hospital compared to the stay of female patients. However, this difference in the periods of stay of male and female patients was not significant $[t=1.469$, $p$ value $=0.142]$. The period of treatment of older adults (50 years and above) was, on an average, 5.29 days. The averages of treatment periods for other 4 groups of adults were 4.77 days for adults of ages $<20$ years, 3.69 days for adults of ages 20-30 years, 2.73 days for adults of ages 30-40 years and 4.19 days for adults of ages 40-50 years. For younger adults and for older adults the duration of treatment was more and the differences in the periods of stay in the hospital by different adults of different ages were significant $[F=3.751, p$-value $=0.000]$. Similar significant differences in the averages of treatment periods in the hospital were observed $[\mathrm{F}=6.882, \mathrm{p}-\mathrm{value}=0.000]$ for the adults of different levels of obesity. The averages were for adults of underweight $=5.34$ days, for normal adults $=5.24$ days, for adults of overweight $=4.76$ days and for obese adults $=5.47$ days. The adults habituated in taking restaurant food were the worst suffers in respect of duration of treatment in the hospital [Average $=5.49$ days $]$ compared to the adults who did not take restaurant food [Average $=4.90$ days]. The difference in the averages was significant $[\mathrm{t}=2.611, \mathrm{p}$-value $=0.009]$. The duration of treatment of adults habituated in taking can food was 4.71 days. This average duration for other group of adults was 4.74 days. There was significant difference in the averages [- $t=$ 2.145 , p-value $=0.032]$.

It was already observed that the NCDs patients spent $36,362.50$ taka per year as treatment cost. But the cost amount was not similar for patients of all age groups. It was observed that the majority $(38.6 \%)$ of the adults belonged to the age group 20-30 years [Table 3] and 40.1 percent of them were patients of at least one of the NCDs and their treatment expenditure was 29,120.00 taka per year with standard deviation 21,504.08 taka. This was the lowest expenditure of treatment. Another big group of (31.6\%) investigated adults were of ages 50 years and above and 65.2 percent of them were affected by at least one of the NCDs. Their treatment expenditure was Tk. 42,335.33 with standard deviation $\sigma=$ Tk. 47,793.02 (monthly average expenditure was 3529.61). This was the highest amount of treatment cost per year. Monthly income of this group of adults was Tk.74,062.50. They spent 4.8 percent of their income for treatment. This percentage was higher than the percentage of income (4.04\%) spent by all the patients. However, this might not be an extra economic burden for the rich people. There was an increasing significant upward treatment cost with the increase in ages of the adults [ $\chi^{2}=88.093$, p-value $=$ $0.000]$. The per annum treatment cost for adults of other age groups were Tk.33,157.89, $\sigma=$ Tk.22,431.80; Tk.32,380.95, $\sigma=$ Tk.26304.94; and Tk. 37,132.35, $\sigma=$ Tk.21,459.88, respectively for ages $<20$ years, 30-40 years and 40-50 years. 
Table 3. Distribution of adults by their age and amount of expenditure for treatment.

\begin{tabular}{|c|c|c|c|c|c|c|c|c|}
\hline \multirow{2}{*}{$\begin{array}{l}\text { Age of adults (in } \\
\text { years) }\end{array}$} & \multicolumn{6}{|c|}{ Expenditure for treatment (000 taka) } & \multicolumn{2}{|c|}{ Total } \\
\hline & $\begin{array}{l}\text { None } \\
\end{array}$ & $<10$ & 10-20 & $20-40$ & $40-60$ & $60^{+}$ & $\mathbf{N}$ & $\%$ \\
\hline \multicolumn{9}{|l|}{$<20$} \\
\hline $\mathrm{N}$ & 17 & 5 & 1 & 6 & 4 & 3 & 36 & 4.5 \\
\hline$\%$ & 47.2 & 13.9 & 2.8 & 16.7 & 11.1 & 0.83 & & \\
\hline \multicolumn{9}{|l|}{$20-30$} \\
\hline $\mathrm{N}$ & 187 & 25 & 35 & 30 & 18 & 17 & 312 & 38.6 \\
\hline$\%$ & 59.9 & 8.0 & 11.2 & 9.6 & 5.8 & 5.4 & & \\
\hline \multicolumn{9}{|l|}{$30-40$} \\
\hline $\mathrm{N}$ & 45 & 6 & 4 & 4 & 1 & 6 & 66 & 8.2 \\
\hline$\%$ & 68.2 & 9.1 & 6.1 & 6.1 & 1.5 & 9.1 & & \\
\hline \multicolumn{9}{|l|}{$40-50$} \\
\hline $\mathrm{N}$ & 70 & 3 & 20 & 16 & 15 & 14 & 138 & 17.1 \\
\hline$\%$ & 50.7 & 2.2 & 14.5 & 11.6 & 10.9 & 10.1 & & \\
\hline \multicolumn{9}{|l|}{$50^{+}$} \\
\hline $\mathrm{N}$ & 89 & 13 & 25 & 43 & 34 & 52 & 256 & 31.6 \\
\hline$\%$ & 34.8 & 5.1 & 9.8 & 16.8 & 13.3 & 20.3 & & \\
\hline \multicolumn{9}{|l|}{ Total } \\
\hline $\mathrm{N}$ & 408 & 52 & 85 & 99 & 72 & 92 & 808 & 100.0 \\
\hline$\%$ & 50.5 & 6.4 & 10.5 & 12.3 & 8.9 & 11.4 & & \\
\hline
\end{tabular}

\section{Discussion}

It was observed that among the investigated adults 49.6 percent were suffering from at least one of the noncommunicable diseases and a big group of them were exclusively $(55.9 \%)$ diabetic patients. Fifty percent adults spending Tk. 60,000.00 and above were diabetic patients. In other studies also $[2,5,19,22]$ the higher proportion of diabetic patients was noted. The worst sufferers in terms of duration (average stay $=5.67$ days, labor hours $=45.36$ ) of treatment in the hospital were the adults who were affected by multiple diseases including diabetes followed by heart patients (average stay in the hospital $=5.34$ days, labor hours $=42.72$ ). Both these groups lost higher labor hours due to disease. Their loss of working hours was more than the per week working hours [39 hours] at national level [24]. This opportunity loss was an economic burden at the household level.

The NCDs affected adults were spending, on an average, Tk. 3030.21 per month. This amount was 4.04 percent of the monthly family income. The economic loss was highest (Tk. $37,132.35$ ) when the affected adults were of ages 50 years and above. This group of adults had monthly income Tk. 74, 062.50 and their economic loss per month for treatment was Tk.3529.61. This loss of income and the opportunity loss due to loss of working hours was the total economic burden for the households. The opportunity loss was incurred more for the adults suffering from multiple diseases. It was also more for obese adults and for adults who were habituated in taking restaurant food.

\section{Conclusion}

The analytical results presented here were based on data collected from some conveniently selected adults by a group of doctors and nurses when they were continuing their academic work leading to M.Ph. degree during 2016-17 session. The total investigated adults was 808. Among them 49.6 percent were affected by at least one of the non-communicable diseases. The biggest group of them (55.9\%) was exclusively diabetic patients, 23.4 percent were diabetic -cum other NCDs and 12.2 percent were suffering from multiple diseases. The male adults were 69.7 percent and NCDs affected male adults were 47.4 percent. Among them 54.7 percent were exclusively diabetic patients. The corresponding percentage among female adults was 58.2. The female adults had 28 percent more risk to be affected by NCDs [Risk Ratio $=1.28]$.

Among the NCDs affected investigating units 71.1 percent were admitted into the hospital and they were treated, on an average, for 4.72 days with standard deviation of 4.35 days. The admitted patients lost 37.75 working hours due the NCDs. This loss was an opportunity loss to the family. The average treatment expenditure per household was Tk. 3030.21 per month as against the monthly family income of Tk. 72,000.00. This expenditure was 4.04 percent of the family income. This loss and the opportunity was the economic burden of the individual family. The opportunity loss was more for male members of the family. They lost, on an average, 39.84 working hours. The economic burden was more in the households due to opportunity loss incurred due to obesity and due to intake of restaurant food and can food.

The economic burden can be reduced if the following aspects can be considered and action can be taken accordingly.

(i) people are to be encouraged for detection of level of obesity and take care of treatment of NCDs,

(ii) people are to be encouraged to avoid unhealthy restaurant foods, can foods and sugary drinks instead of pure drinking water. They should take home made food as per possible,

(iii) people are to be encouraged to take more fruits and vegetables and fewer foods high in sugar, salts and saturated fats to avoid diabetes,

(iv) People are to be suggested to avoid sedentary works rather doing physical labor, 
(v) Urban people can be advised to walk to their nearby working place and they should develop a habit of morning and/or evening walk to avoid obesity and diabetes.

The health authority can play a decisive role to implement the above proposals. The community can do a lot in achieving the target of reducing the prevalence of NCDs.

\section{References}

[1] Zhang, Q. L.; Rothon bacher, D. (2008): Prevalence of kidney disease in population -based studies: Systematic review, BMC Public Health, 8, 117. doi: 10.1186/1471-2458-117.

[2] WHO (2018): Fact sheets / detail/obesity-and-overweight: February 2018, http//www.who.it/news-room.

[3] International Diabetes Federation (IDF) (2011): Country estimates table, IDF Diabetes atlas, $6^{\text {th }}$ edition.

[4] Saquib, N.; Saquib, J.; Ahmed, T,; Khanam, M. A.; Cullen, M. R. (2012): Cardiovascular diseases and type II diabetes in Bangladesh: a systematic review and meta- analysis of studies between 1995-2010, BMC Public Health, 12, 434.

[5] Bhuyan, K. C.; Ahmed, Md. M. and Fardus, J. (2017): Socioeconomic factors associated with overweight an obesity: A case study among adult people of Bangladesh, AJSE, 16 (2) 119-124.

[6] Bhuyan, K. C.; Fardus, J. and Khanam, M. (2016): Discriminating the students of universities by their smoking habit, AJSE, 15 (1).

[7] WHO (2005): Preventing chronic diseases a vital investment cataloguing -in- publication data, World Health Organization.

[8] Abegunde, D. O. and Stanciole, A. (2006): An estimation of the economic impact of chronic non-communicable diseases in selected countries. WH O Working Paper, Geneva, World Health Organization, Department of Chronic Diseases and Health Promotion.

[9] Abegunde, D. O.; Mathers, C. D; Adam, T; Ortegon, M. and Strong, K. (2007): The burden and costs of chronic diseases in low-income and middle-income countries, Lancet, 370 (9603), 1929-1938.

[10] Mayer-Foulkes, D. (2011): A survey of Macro Damages from Non-Communicable Chronic Diseases: Another Challenges for Global Governance, Global Economy Journal, 11 (1).

[11] Nikolic, I. A.; Stanciole, A. E. and Zaydman, M. (2011): Chronic Emergency: Why NCDs matter, Washington, D. C., World Bank.
[12] Suhrcke, M; Nugent, R. A.; Stuckler, D. and Rocco, L. (2006): Chronic Disease: An Economic Perspective. Oxford, U.K.: Oxford Health Alliance.

[13] Chow, K.; Teo, K. K. Rangarajon et al (2013): Prevalence, awareness, treatment and control of hypertension in urban and rural communities in high - , middle-and low-income countries, JAMA, 310, 959-968.

[14] Kundu, M. K.; Hazra, S.; Pal, D. and Bhattacharya, M. (2018): A review of non-communicable diseases burden, its socioeconomic impact and the strategies for prevention and control of NCDs in India, Indian Journal Public Health, 62 (4), 302-304. doi: 10.4103/ijph.IJPH_324_16.

[15] Saito, E.; Gilmour, S.; rahaman, M. M.; Gautam, G. S.; Shrestha, P. K. and Shibuya, K. (2014): Catastrophic household expenditure on health in Nepal: A cross-sectional survey. Bull. World Health Organization, 92, 760-767.

[16] seema, R.; Marryam, T.; Fadzai, M.; Tinatsei, C.; Tiisetsl, M. and Sunith, S. (2015): Economics of non-communicable diseases: Case study of South Africa and India, Indian Journal of Pharmacy Ptactice, 8 (3), 90-97. doi: 10.5530/ijopp.8.3.2.

[17] Alan, K. and Mahal, A. (2014): economic impacts of health shocks on households in low- and middle-income countries: A review of the literature, Global Health, 10, 21.

[18] Engelgau, M. M; Karan. A. and Mahal, A. (2012): The economic impact of NCDs on household in India, Global Health, 8, 9.

[19] Bhuyan, K. C. and Fardus, J. (2019): level of obesity and socioeconomic factors of a group of adult people of Bangladesh: A factor analysis approach, Amer, Jour. Data Mining and Knowledge Discovery, 4 (1), 8-14, doi: 10.11648/j.ajdmkd.20190401.12.

[20] Paymane, A. and Miranda, P. (2018): Images of measurements of obesity, BMJ, 360. doi: https// doi.org/10.1136/method bmj.k.1274.

[21] Mokdad, A. H.; Ford, E. S.; Bowman, B. A.; Dietz, W. H.; Vinicor, F.; Bales, V. S. et al (2003): Prevalence of obesity, diabetes, and obesity-related health risk factors 2001, JAMA, 289, 76-79.

[22] Akter, S.; Rahaman, M. M.; Sarah, K. A.; and Sultan, P. (2014): Prevalence of diabetes and pre-diabetes and their risk factors among Bangladeshi adults: A Nationwide survey, Bulletin of the WHO, 92, 204-213 A.

[23] Bhuiyan, D. and Bhuyan, K. C. (2019): Discriminating Bangladeshi Adults by Non-Communicable Diseases, Rehibilitation Science, 4 (3), 33-43, doi: 10.1168/j.rs.20190430.11

[24] BBS (2017): Bangladesh Statistics-2, Bangladesh Bureau of Statistics, Dhaka. 